\title{
Inhibition of Na-K-Cl cotransporter isoform 1 reduces lung injury induced by ischemia-reperfusion
}

\author{
Chou-Chin Lan, MD, PhD, , ${ }^{\text {,b }}$ Chung-Kan Peng, MD, PhD, ${ }^{c}$ Shih-En Tang, MD, PhD, ${ }^{c}$ \\ Hsueh-Ju Lin, MS, PhD, ${ }^{\mathrm{d}}$ Sung-Sen Yang, MD, PhD, ${ }^{e}$ Chin-Pyng Wu, MD, PhD, ${ }^{\mathrm{f}}$ and \\ Kun-Lun Huang, $\mathrm{MD}, \mathrm{PhD}^{\mathrm{c}, \mathrm{d}}$
}

\begin{abstract}
Objectives: Ischemia-reperfusion acute lung injury is characterized by increased vascular permeability, lung edema, and neutrophil sequestration. Ischemia-reperfusion acute lung injury occurs in lung transplantation and other major surgical procedures. Effective regulation of alveolar fluid balance is critical for pulmonary edema. Sodium-potassium-chloride co-transporter regulates alveolar fluid and is associated with inflammation. We hypothesized that sodium-potassium-chloride co-transporter is important in ischemia-reperfusion acute lung injury. Bumetanide, a sodium-potassium-chloride co-transporter inhibitor, is used to treat pulmonary edema clinically. We studied the effect of bumetanide in ischemiareperfusion acute lung injury.
\end{abstract}

Methods: Isolated perfusion of mouse lungs in situ was performed. The main pulmonary artery and left atrium were catheterized for lung perfusion and effluent collection for recirculation, respectively, with perfusate consisting of $1 \mathrm{~mL}$ blood and $9 \mathrm{~mL}$ physiologic solution. Ischemia-reperfusion was induced by 120 minutes of ischemia (no ventilation or perfusion) and reperfused for 60 minutes. Wild-type, SPAK knockout $\left(\mathrm{SPAK}^{-/-}\right)$, and WNK4 knockin $\left(\mathrm{WNK} 4^{\mathrm{D} 561 \mathrm{~A} /+}\right.$ ) mice were divided into control, ischemia-reperfusion, and ischemiareperfusion + bumetanide groups $(n=6$ per group). Bumetanide was administered via perfusate during reperfusion. Measurements were taken of lung wet/ dry weight, microvascular permeability, histopathology, cytokine concentrations, and activity of the nuclear factor- $\kappa \mathrm{B}$ pathway.

Results: In wild-type mice, ischemia-reperfusion caused lung edema (wet/dry weight $6.30 \pm 0.36$ ) and hyperpermeability (microvascular permeability, $0.29 \pm 0.04)$, neutrophil sequestration $(255.0 \pm 55.8$ cells/high-power field $)$, increased proinflammatory cytokines, and nuclear factor- $\kappa \mathrm{B}$ activation $(1.33 \pm 0.13)$. Acute lung injury was more severe in WNK4 mice with more lung edema, permeability, neutrophil sequestration, and nuclear factor- $\kappa$ B activation. Severity of acute lung injury was attenuated in $\mathrm{SPAK}^{-1-}$ mice. Bumetanide decreased pulmonary edema (wild-type: wet/dry weight $5.05 \pm 0.44$, WNK4: wet/dry weight $5.13 \pm 0.70$ ), neutrophil sequestration (wild-type: $151.7 \pm 27.8$ cells/high-power field, WNK4: $135.3 \pm 19.1$ cells/high-power field), permeability (wild-type: $0.19 \pm 0.01$, WNK4: $0.21 \pm 0.03$ ), cytokines, and nuclear factor- $\kappa \mathrm{B}$ activation after ischemia-reperfusion.

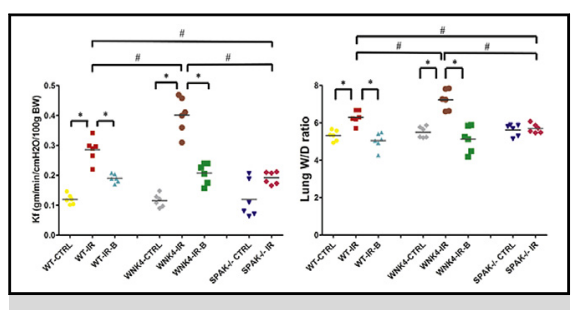

Higher NKCC1 leads to severe lung injury with higher edema, permeability, and inflammation.

\section{Central Message}

Higher NKCC1 leads to more severe ALI with greater lung edema, permeability, and neutrophil sequestration. Manipulations that decrease NKCC1 can attenuate the severity of lung injury.

\section{Perspective}

NKCC1 regulates ion transport and fluid balance in the lungs. NKCC1 may play a critical role in ALI. However, the study on the role of NKCC1 in IR-induced ALI is lacking. Our study found that NKCC1 plays an important role in IR-induced ALI. Genetic and pharmacologic manipulation to decrease NKCC1 can attenuate ALI by suppressing the $\mathrm{NF}-\kappa \mathrm{B}$ pathway.

See Editorial Commentary page 216.

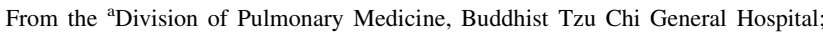
${ }^{\mathrm{b}} \mathrm{S}$ chool of Medicine, Tzu-Chi University, Hualien; ${ }^{\mathrm{c}}$ Division of Pulmonary Medicine, National Defense Medical Center, Tri-Service General Hospital; ${ }^{\mathrm{d}}$ Institute of Undersea and Hyperbaric Medicine, National Defense Medical Center; ${ }^{\mathrm{e} D i v i s i o n}$ of Nephrology, Tri-Service General Hospital, National Defense Medical Center, Taipei; and ${ }^{\mathrm{f}}$ Department of Critical Care Medicine, Li-Shin Hospital, Tao-Yuan County, Taiwan, Republic of China

This study was supported by grants from the National Science Council of Taiwan (NSC100-2314-B-706-001-MY3), Tri-Service General Hospital (TSGH-C104087), Landseed Hospital (LSH-2014-02), and Buddhist Tzu-Chi General Hospital (TCRD-TPE-103-38).
}

K-L.H. and C-P.W contributed equally to this work.

Received for publication Jan 14, 2016; revisions received Sept 23, 2016; accepted for publication Sept 28, 2016.

Address for reprints: Kun-Lun Huang, MD, PhD, Institute of Undersea and Hyperbaric Medicine, National Defense Medical Center, 161 Ming-Chuan East Rd, Section 6, Neihu 114, Taipei, Taiwan, ROC (E-mail: kun@ndmetsgh.edu.tw). $0022-5223 / \$ 36.00$

Copyright (C) 2016 by The American Association for Thoracic Surgery http://dx.doi.org/10.1016/j.jtcvs.2016.09.068 


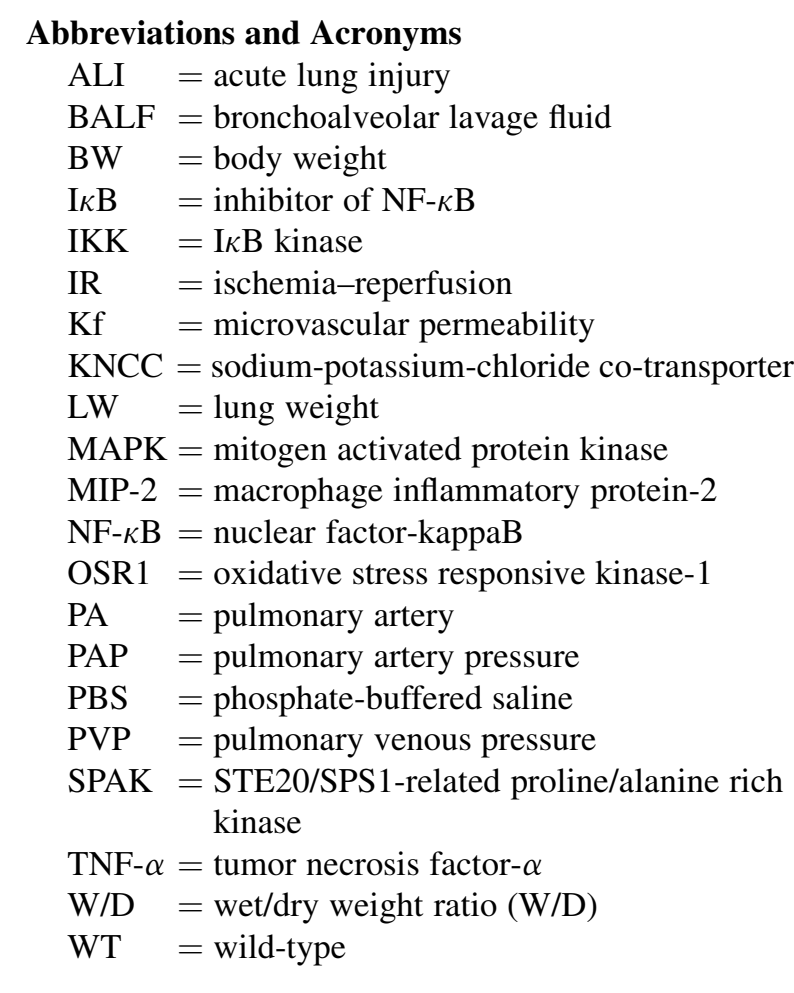

Scanning this QR code will take you to a video for the article.

Conclusions: Functional reduction of sodium-potassiumchloride co-transporter by genetic or pharmacologic treatment to inhibit sodium-potassium-chloride co-transporter resulted in lower severity of acute lung injury induced by ischemia-reperfusion. Sodium-potassium-chloride cotransporter may present a promising target for therapeutic interventions in a clinical setting. ( $\mathrm{J}$ Thorac Cardiovasc Surg 2017;153:206-15)

Acute lung injury (ALI) induced by ischemia-reperfusion (IR) occurs when the lungs are exposed to periods of IR. ${ }^{1}$ ALI is characterized by increased pulmonary vascular permeability, lung edema, neutrophil sequestration, and hypoxemia. ${ }^{1}$ IR-induced ALI occurs in many clinical situations, including lung transplantation, cardiopulmonary bypass, and other major surgical procedures. ${ }^{2,3}$ Lung transplantation provides a curative therapy for patients with end-stage lung diseases. However, the shortage of donor organs remains a major limiting factor in the widespread application of lung transplantation. ${ }^{4}$ Despite advances in organ preservation and perioperative care, IRinduced ALI remains a significant cause of mortality and morbidity after lung transplantation. ${ }^{4}$ Therefore, there is an increasing effort to study IR-induced ALI to improve outcomes in lung transplantation.

Alveolar fluid regulation is considered to have a critical role in the development of pulmonary edema in lung injury. Ion channels in the lung epithelium regulate water influx and efflux and are likely to be important in IR-induced ALI. However, previous studies on the role of ion channels in IR-induced ALI have been inconclusive, and the role of ion channels in ALI is still not fully understood. To gain a better understanding of the role of fluid regulation in lung injury, studies that address the underlying mechanisms and the involvement of ion channels will be important. This may lead to new therapeutic options for the management of ALI.

The sodium-potassium-chloride co-transporter (NKCC) regulates intracellular volume by coupling the transport of sodium $\left(\mathrm{Na}^{+}\right)$, chloride $\left(\mathrm{Cl}^{-}\right)$, and potassium $\left(\mathrm{K}^{+}\right){ }^{7}$ Two isoforms of the NKCC have been identified: NKCC1 and NKCC2. Only NKCC1 is expressed in alveolar epithelial cells, whereas NKCC2 expression is restricted to the kidney. ${ }^{7} \mathrm{NKCC} 1$ is located basolaterally in the lung epithelium that mediates a net influx of ions into cells. ${ }^{8}$ Therefore, the chemical gradient that creates the driving force for water transport is mediated primarily by NKCC1.

The activity of epithelial NKCC1 is regulated by a phosphorylation signaling cascade consisting of with-nolysine kinase (WNK), oxidative stress responsive kinase1 (OSR1), and STE20/SPS1-related proline/alanine rich kinase (SPAK). ${ }^{9}$ SPAK and OSR1 are downstream substrates of WNK1 and WNK4 kinases and upstream regulators of NKCC1. ${ }^{9}$ Activation of WNK4 has been shown to activate the OSR1/SPAK phosphorylation cascade. ${ }^{9}$ Phosphorylated OSR1 and SPAK are known to phosphorylate NKCC1. ${ }^{9}$ Although it is well documented that the WNK-SPAK pathway plays a crucial role in systemic salt and water homoeostasis, ${ }^{9}$ its role in regulating pulmonary fluid clearance is largely unknown. Nuclear factor-kappaB (NF- $\kappa$ B) and proinflammatory cytokines, including interleukin-6, macrophage chemoattractant protein-1, and tumor necrosis factor- $\alpha$ (TNF- $\alpha$ ), play important roles in lung injury. ${ }^{10} \mathrm{~A}$ study exploring the central role for NF- $\kappa \mathrm{B}$ in the induction of lung injury revealed that NF- $\kappa$ B is a critical regulator of the inflammatory response in lung injury, with inhibition of NF- $\kappa \mathrm{B}$ activation, reduction of IR injury, and improvement of pulmonary graft function. ${ }^{11} \mathrm{NF}-\kappa \mathrm{B}$ also plays a critical role in SPAK regulation. ${ }^{10}$ During IR, the NF- $\kappa \mathrm{B}$ pathway is activated and regulates not only proinflammatory cytokines but also SPAK and NKCC1 activity. ${ }^{10}$ Thus, we hypothesized that the pathogenic mechanisms underlying ALI 


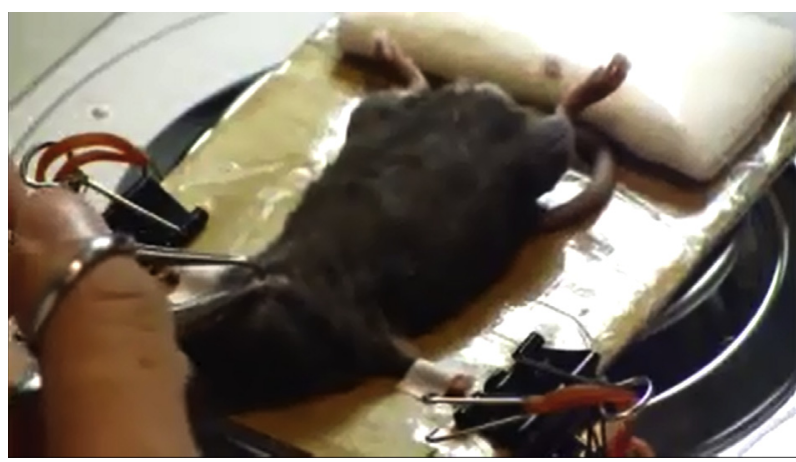

VIDEO 1. Isolated perfusion of lungs in situ was performed. After deep anesthesia, tracheostomy was performed and a cannula was inserted into the trachea. The mice were ventilated via a rodent ventilator. The chest was opened by median sternotomy, and $1 \mathrm{~mL}$ of intracardiac blood was withdrawn. A catheter was inserted into the main PA after performing a right ventriculotomy. The other end of the catheter was connected to a tube for pulmonary perfusion. After a small incision of the left ventricle, the catheter was inserted into the left atrium via a left ventriculotomy. This catheter was placed in the left atrium to collect the effluent perfusate for recirculation. The pulmonary circulation was maintained in a closed circuit via a peristaltic pump. During the experiment, LW and Kf were measured at baseline and post-IR. PAP was measured using a pressure sensor, which was connected to the pulmonary arterial catheter. Video available at: http://www.jtcvsonline.org/article/S0022-5223(16)31384-8/ addons.

involve an interplay among NKCC1, NF- $\kappa \mathrm{B}$, and proinflammatory cytokines.

Because NKCC1 is important in fluid and inflammation regulation, we hypothesized that $\mathrm{NKCC} 1$ should be important in IR-induced ALI. WNK4 $4^{\mathrm{D} 561 \mathrm{~A} /+}$ knockin mice are identified as having increased expression of $\mathrm{NKCC} 1$ through the activation of the OSR1/SPAK-NKCC1 phosphorylation cascade. ${ }^{12} \mathrm{SPAK}^{-1-}$ mice, in contrast, are identified as having very low NKCC1 function. ${ }^{13}$ In addition, bumetanide is a known drug to inhibit NKCC1. ${ }^{14}$ Bumetanide is a potent loop diuretic that produces a rapid and marked diuresis. ${ }^{14}$ Its principal site of action is the loop of Henle in kidney. ${ }^{14}$ For NKCC1 present in lung tissues, ${ }^{7}$ bumetanide should have an effect in lung injury. The aim of the present study was to determine the role of NKCC1 in IR-induced ALI via genetic and pharmacologic manipulations.

\section{MATERIALS AND METHODS \\ Animals}

$\mathrm{WNK}^{\mathrm{D} 561 \mathrm{~A} /+}$ knockin, $\mathrm{SPAK}^{-/-}$, and wild-type (WT) mice were used in this study. SPAK ${ }^{-/-}$and WNK4 ${ }^{\mathrm{D} 561 \mathrm{~A} /+}$ mice were generated as described previously. ${ }^{12,15}$ Male mice aged 10 to 12 weeks were used in this study.

The National Science Council and Animal Review Committee of the National Defense Medical Center (Taipei, Taiwan) approved the study protocol. The animals were cared for in accordance with the "Guide for the Care and Use of Laboratory Animals," published by the US National Institutes of Health.

\section{Isolation and Perfusion of Lungs}

The video and schematic diagram indicating the experimental procedure for isolation and perfusion of lungs are shown in Video 1 and Figure 1. Procedures regarding the preparation of isolated-perfused lungs in situ were performed as previously described. ${ }^{16}$ Mice were anesthetized through intraperitoneal injection of Zoletil $(20 \mathrm{mg} / \mathrm{kg}$; Virbac, Carros, France).

After confirmation of deep anesthesia, tracheostomy was performed and a cannula (Becton Dickinson, Franklin Lakes, NJ) was inserted into the trachea. After tracheostomy, mice were ventilated with a gas mixture containing $2.5 \% \mathrm{CO}_{2}$ in $97.5 \%$ air using a rodent ventilator. Respiratory rate was maintained at 90 breaths $/ \mathrm{min}$, tidal volume was maintained at $0.5 \mathrm{~mL}$, and end-expiratory pressure was maintained at $1 \mathrm{~cm} \mathrm{H}_{2} \mathrm{O}$. The chest was opened by median sternotomy, and heparin $(500 \mathrm{U})$ was injected into the right ventricle to prevent blood coagulation; $1 \mathrm{~mL}$ of intracardiac blood was withdrawn. After a right ventriculotomy, a catheter was inserted into the main pulmonary artery (PA), and the PA and ascending aorta were tied together using a silk suture. Pulmonary artery pressure (PAP) was measured using a pressure sensor, which was connected to the PA catheter. The other end of the catheter was connected to a tube for pulmonary perfusion. After a small incision of the left ventricle, the catheter was inserted into the left atrium via a left ventriculotomy, and the catheter was used to collect the effluent perfusate for recirculation. The pulmonary circulation was maintained in a closed circuit via a peristaltic pump (Model 1203, Harvard Apparatus). The peristaltic pump (Gilson Inc, Villiers le Bel, France) was used to perfuse the lungs with recirculated perfusate. The perfusate consisted of $1 \mathrm{~mL}$ blood mixed with $9 \mathrm{~mL}$ physiologic salt solution $(119 \mathrm{mmol} / \mathrm{L} \mathrm{NaCl}, 4.7 \mathrm{mmol} / \mathrm{L} \mathrm{KCl}, 1.17 \mathrm{mmol} / \mathrm{L} \mathrm{MgSO}$, $22.6 \mathrm{mmol} / \mathrm{L} \quad \mathrm{NaHCO}_{3}, 1.18 \mathrm{mmol} / \mathrm{L} \mathrm{KH}_{2} \mathrm{PO}_{4}, 1.6 \mathrm{mmol} / \mathrm{L} \mathrm{CaCl}_{2}$, $5.5 \mathrm{mmol} / \mathrm{L}$ glucose, and $50 \mathrm{mmol} / \mathrm{L}$ sucrose). Bovine albumin $(4 \mathrm{~g} / \mathrm{dL})$ was added to maintain the osmolarity of the perfusate. The perfusion rate was maintained at $1 \mathrm{~mL} / \mathrm{min}$ using a roller pump and kept at constant temperature $\left(37^{\circ} \mathrm{C}\right)$ using a water bath.

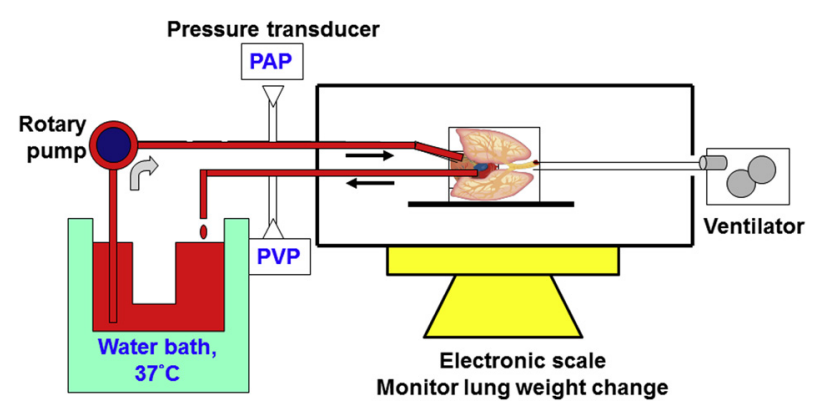

FIGURE 1. Isolated lung model. After confirmation of deep anesthesia, tracheostomy was performed and a cannula was inserted into the trachea. Mice were ventilated with a gas mixture containing $2.5 \% \mathrm{CO}_{2}$ in $97.5 \%$ air via a rodent ventilator. The chest was opened by median sternotomy, and heparin $(500 \mathrm{U})$ was injected into the right ventricle to prevent blood coagulation. After a right ventriculotomy, a catheter was inserted into the main PA, and the PA and ascending aorta were tied together using a silk suture. PAP was measured using a pressure sensor, which was connected to the PA catheter. The other end of the catheter was connected to a tube for pulmonary perfusion. After a small incision of the left ventricle, the catheter was inserted into the left atrium via a left ventriculotomy. This catheter was placed in the left atrium to collect the effiuent perfusate for recirculation. The pulmonary circulation was maintained in a closed circuit via a peristaltic pump. $P A P$, Pulmonary artery pressure; $P V P$, pulmonary venous pressure. 


\section{Experimental Protocols and Induction of Acute Lung Injury Induced by Ischemia-Reperfusion}

TheWNK ${ }^{\mathrm{D} 561 \mathrm{~A} /+}$ knockin, $\mathrm{SPAK}^{-1-}$, and WT mice were allocated to control (WT, $\mathrm{WNK}^{\mathrm{D} 561 \mathrm{~A} /+}$, and $\mathrm{SPAK}^{-{ }^{-}-}$), IR (WT-IR, WNK $\mathrm{W}^{\mathrm{D} 61 \mathrm{~A} /+}-\mathrm{IR}$, $\mathrm{SPAK}^{-1-}$-IR), and IR + bumetanide groups (WT-IR-B, WNK ${ }^{\mathrm{D} 561 \mathrm{~A} / \mathrm{+}}$ IR-B) $(\mathrm{n}=6$ per group). Bumetanide $(1 \mu \mathrm{g} / \mathrm{mL})$ was administered via the perfusate at the time of reperfusion. Because of low NKCC1 levels, bumetanide was not administered in $\mathrm{SPAK}^{-1-}$ mice.

The IR-induced ALI was performed with 120 minutes of ischemia by stopping ventilation and perfusion of deflated lung. The lungs were then reperfused and ventilated for 60 minutes. During the procedure, measurements of lung weight (LW) and microvascular permeability (Kf) were taken at baseline and post-IR. In the control group, IR was not performed and the second measurements were taken after 180 minutes at the same time as in the IR group. We continuously monitored PAP and left atrial pressures, which represent the pulmonary venous pressure (PVP). We recorded the PAP before IR injury as baseline PAP. Changes of PAP during IR were calculated for each time point by subtracting baseline PAP.

The hilum of the right lungs was ligated, and the right upper and lower lobes were removed for immunoblotting. The right middle lobe was excised for analysis of wet/dry weight ratio (W/D). The remaining left lung was lavaged twice with $0.5 \mathrm{~mL}$ phosphate-buffered saline (PBS), and the bronchoalveolar lavage fluid (BALF) was centrifuged at $200 \mathrm{~g}$ for 10 minutes. Concentrations of total protein, TNF- $\alpha$, and macrophage inflammatory protein-2 (MIP-2) in BALF were measured. Histopathologic examination was processed on the right lung in a separate procedure.

\section{Microvascular Permeability}

An index of $\mathrm{Kf}$ is determined from the $\mathrm{LW}$ change induced by elevated PVP. ${ }^{17}$ During ventilation and perfusion, the PVP was rapidly elevated by $10 \mathrm{~cm} \mathrm{H}_{2} \mathrm{O}$ for 7 minutes. The slow, steady phase of weight gain as a function of time $(\Delta \mathrm{W} / \Delta \mathrm{T})$ was plotted on a semilogarithmic paper and then extrapolated to zero time to obtain the initial rate of transcapillary filtration. From this plot, Kf was defined as the y-intercept $(\mathrm{g} / \mathrm{min})$ divided by PVP and $\mathrm{LW}$, and expressed in whole units of grams per minute per centimeter of $\mathrm{H}_{2} \mathrm{O}$ multiplied by $100 \mathrm{~g}$. ${ }^{17}$

\section{Total Protein Concentration and Cytokine Levels in Bronchoalveolar Lavage Fluid}

Total protein concentration in the supernatant was determined using the bicinchoninic acid protein assay (Pierce, Rockford, Ill). Concentrations of TNF- $\alpha$ and MIP-2 levels were determined using a commercially available enzyme-linked immunosorbent assay (R\&D Systems Inc, Minneapolis, Minn).

\section{Pulmonary Edema}

The right middle lobe was removed, and the wet weight was determined. The lung was then dried in an oven at $60^{\circ} \mathrm{C}$ for 48 hours. The wet and dry weights were measured to calculate the lung W/D.

\section{Lung Histopathology}

The tissues were immersed in $10 \%$ formaldehyde fixative for 24 hours and then embedded in paraffin wax and cut into $2 \mu \mathrm{m}$-thick sections using a microtome. The sections were stained with hematoxylin-eosin to assess the interstitial edema and the degree of neutrophil sequestration. The number of neutrophils in the interstitium and alveoli was determined as the average number of neutrophils per high-power field $(400 \times)$. A minimum of 10 fields were randomly examined by an observer blinded to the study. ${ }^{18}$ Lung injury also was scored according to (1) infiltration or aggregation of neutrophils in the airspace or vessel wall and (2) thickness of the alveolar wall. Each assessment was graded $0,1,2$, or 3 corresponding to no, mild, moderate, or severe injury, respectively. ${ }^{19}$

\section{Immunoblotting}

Cytoplasmic and nuclear proteins were extracted from frozen lung tissues with the Nuclear/Cytosol Extraction kit (BioVision, Inc, Mountain View, Calif) according to the manufacturer's instructions. Protein concentrations were determined using the bicinchoninic acid protein assay, and equal amounts of lung homogenates ( $30 \mu \mathrm{g} / \mathrm{lane})$ were fractionated on $10 \%$ to $12 \%$ sodium dodecyl sulfate-polyacryl-amide gel electrophoresis gels and transferred to Hybond polyvinylidene fluoride membranes (Millipore, Schwalbach, Germany). The membranes were blocked by incubation in PBS containing $0.1 \%$ Tween 20 and 5\% nonfat milk for 1 hour at room temperature. Blots were incubated with antibodies to NKCC1, phosphorylated-NF- $\kappa$ B p 65 , inhibitor of NF- $\kappa$ B (I $\kappa$ B)- $\alpha$, phosphorylated $\mathrm{I} \kappa \mathrm{B}$ kinase (IKK)- $\beta$, and total IKK (Cell Signaling Technology, Danvers, Mass) overnight at $4{ }^{\circ} \mathrm{C}$. The blots were then washed 3 times for 10 minutes in PBS containing $0.1 \%$ Tween 20 . The blots were incubated with horseradish peroxidase linked anti-rabbit immunoglobulin $\mathrm{G}(1: 40,000)$ or antigoat immunoglobulin $\mathrm{G}(1: 50,000)$ for 1 hour at room temperature and then washed 3 times in PBS containing $0.1 \%$ Tween 20 for 10 minutes. Bands were visualized using enhanced chemiluminescence reagents and exposure to radiography film. The blots were then stripped and incubated with an anti-TATA antibody (for nuclear protein, diluted 1:1000; Abcam, Cambridge, Mass) or anti- $\beta$-actin antibody (for cytoplasmic protein, diluted 1:10,000; Sigma, St Louis, Mo) to ensure equal loading.

\section{Data Analysis}

All statistical analyses were performed using SPSS version 18.0 (SPSS Inc, Chicago, Ill). All of the values are reported as means \pm standard deviation. Differences between groups were evaluated using the KruskalWallis test followed by post hoc comparisons with Games Howell tests (for intergroup comparison). The generalized estimating equation method was used to examine changes in PAP during the reperfusion period across the times in different groups.

\section{RESULTS \\ Changes of Pulmonary Artery Pressure After Ischemia-Reperfusion}

Changes of PAP are shown in Figure 2. In the control group, PAP did not significantly change throughout the 60-minute observation period. After IR, PAP showed a bimodal change during the 60-minute reperfusion period. An initial rapid increase in the perfusion pressure was followed by a steady phase of gradual increase. Changes of PAP were greater in WNK4 ${ }^{\mathrm{D} 561 \mathrm{~A} /+}$ knockin and WT mice and lower in $\mathrm{SPAK}^{-1-}$ mice after IR $(P<.05$ compared with the WT-IR group). In SPAK $^{-1-}$ mice, changes of PAP after IR were similar to the control group. In the IR + bumetanide group (IR-B), bumetanide abolished the PAP elevation in WNK4 ${ }^{\mathrm{D} 561 \mathrm{~A} /+}$ knockin and WT mice $(P<.05$ compared with IR). Changes of PAP were less in $\mathrm{SPAK}^{-1-}$ or bumetanide-treated mice, which had lower NKCC1 function.

\section{Changes of Lung Weight After Ischemia-Reperfusion}

The LW/body weight (LW/BW) and W/D are shown in Figure 3. The lung LW/BW was similar across control groups $(P>.05)$ (Figure 3, $A)$. After IR, the LW/BW was 

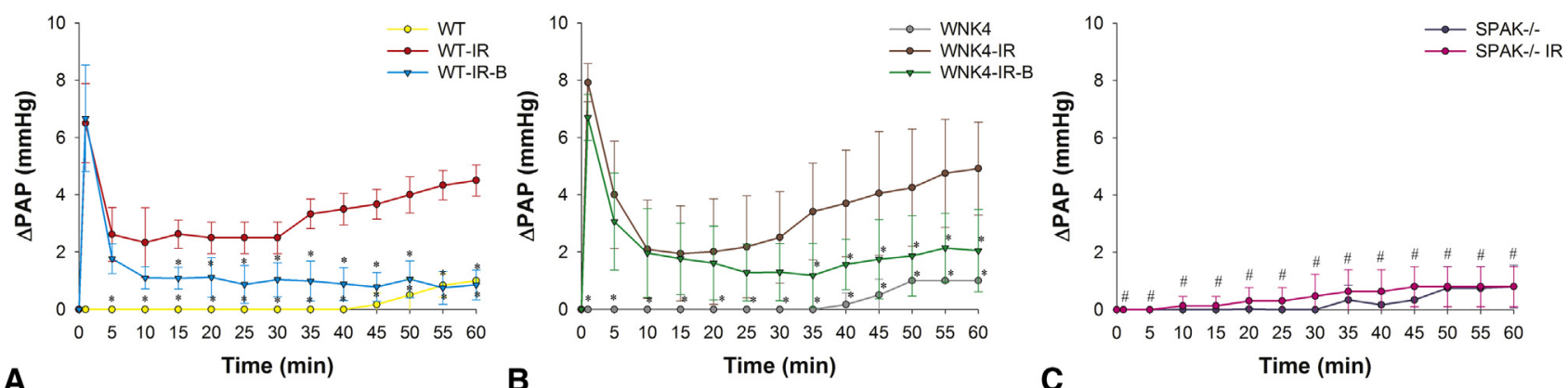

FIGURE 2. Changes of PAP after IR. In the control group, PAP did not change significantly throughout the 60-minute observation period. After IR, PAP showed a bimodal change during the 60-minute reperfusion period. An initial rapid increase in the perfusion pressure was followed by a steady phase of gradual increase. Changes of PAP were greater in WNK4 ${ }^{\mathrm{D} 561 \mathrm{~A} /+}$ knockin and WT mice and lower in SPAK ${ }^{-1-}$ mice after IR $(P<.05$ compared with the WT-IR group). In SPAK ${ }^{-1-}$ mice, changes in PAP after IR were similar to those in the control group. In the IR + bumetanide group, bumetanide abolished the PAP elevation in WNK4 ${ }^{\mathrm{D} 561 \mathrm{~A} /+}$ knockin and WT mice $(P<.05$ compared with IR). *Significantly different from IR in each group $(P<.05)$. \#Significantly different among WT-IR, WNK4-IR, and SPAK ${ }^{-1-}$-IR $(P<.05)$. A, WT, WT with IR (WT-IR), and WT-IR with bumetanide (WT-IR-B).

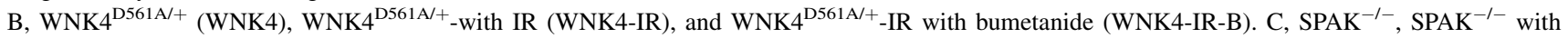
IR (SPAK ${ }^{-1-}$-IR). PAP, Pulmonary artery pressure; $W T$, wild-type; $I R$, ischemia-reperfusion; $W N K 4^{D 561 A /+}$, with-no-lysine kinase 4 knockin; $S P A K$, STE20/SPS1-related proline/alanine rich kinase knockout.

significantly increased and higher in $\mathrm{WNK} 4^{\mathrm{D} 561 \mathrm{~A} /+}$-IR than in WT-IR and SPAK $^{-1-}$-IR $(P<.05$ compared with WT-IR group). LW/BW was decreased in both WNK4 $4^{\mathrm{D} 561 \mathrm{~A} /{ }^{+}}$-IR$\mathrm{B}$ and WT-IR-B (both $P<.05$ compared with IR). Lung W/D was similar across the control groups $(P>.05)$ (Figure 3, B). After IR, lung W/D was significantly increased and higher in WNK $4{ }^{\mathrm{D} 561 \mathrm{~A} /+}$ knockin mice than in WT mice and SPAK $^{-1-}$ mice $(P<.05$ compared with WT-IR group). Lung W/D was decreased both in
WNK4 $4^{\mathrm{D} 561 \mathrm{~A} /+}$-IR-B and WT-IR-B (both $P<.05$ compared with IR). The pulmonary edema was less severe in $\mathrm{SPAK}^{-1-}$ or bumetanide-treated mice, which had lower NKCC1 function.

\section{Changes of Microvascular Permeability After Ischemia-Reperfusion}

Kf was similar in the control groups $(P>.05)$ (Figure 4). $\mathrm{Kf}$ was significantly increased compared with baseline after
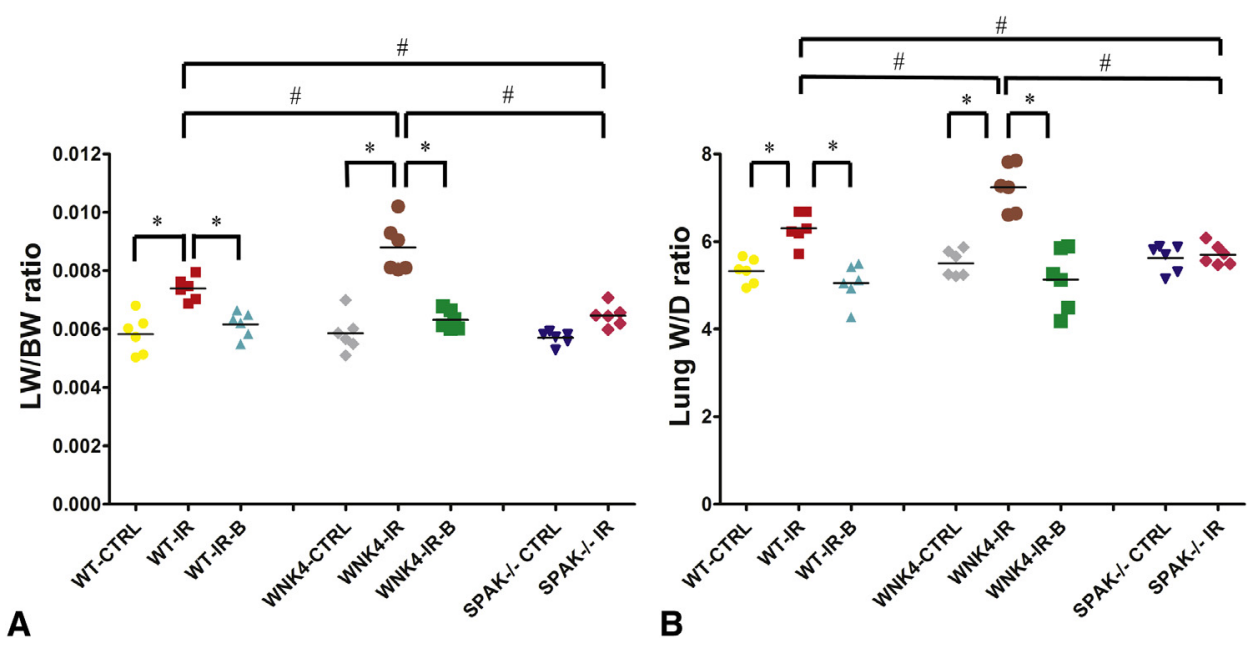

FIGURE 3. Pulmonary edema after IR. A, Lung LW/BW was similar across control groups $(P>.05)$. After IR, LW/BW was significantly increased and higher in WNK $4^{\mathrm{D} 561 \mathrm{~A} /+}$-IR than in WT-IR and SPAK ${ }^{-/-}$-IR $(P<.05$ compared with WT-IR group $)$. LW/BW was decreased in both WNK4 ${ }^{\mathrm{D} 561 \mathrm{~A} /+}-$-IR-B and WT-IR-B (both $P<.05$ compared with IR). B, Lung W/D was similar across the control groups $(P>.05)$. After IR, lung W/D was significantly increased and higher in WNK4 ${ }^{\mathrm{D} 561 \mathrm{~A} /+}$ knockin mice than in WT mice and SPAK ${ }^{-/-}$mice $(P<.05$ compared with WT-IR group). Lung W/D was decreased in WNK4IR-B and WT-IR-B (both $P<.05$ compared with IR). *Significantly different from IR in each group $(P<.05)$. \#Significantly different among WT-IR, WNK4-IR, and SPAK ${ }^{-1-}$-IR $(P<.05)$. IR, Ischemia-reperfusion; $L W / B W$, lung weight/body weight; $S P A K$, STE20/SPS1-related proline/alanine rich kinase knockout; SPAK ${ }^{-1-}-C T R L, \mathrm{SPAK}^{-1-}$ with control; SPAK ${ }^{-1-}-I R, \mathrm{SPAK}^{-1-}$ with IR; W/D, lung wet/dry weight ratio; WNK4-CTRL, WNK4 ${ }^{\mathrm{D} 561 \mathrm{~A} /+}$ with con-

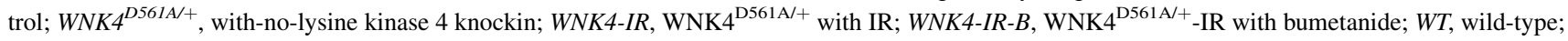
WT-CTRL, WT with control; WT-IR, WT with IR; WT-IR-B, WT-IR with bumetanide. 


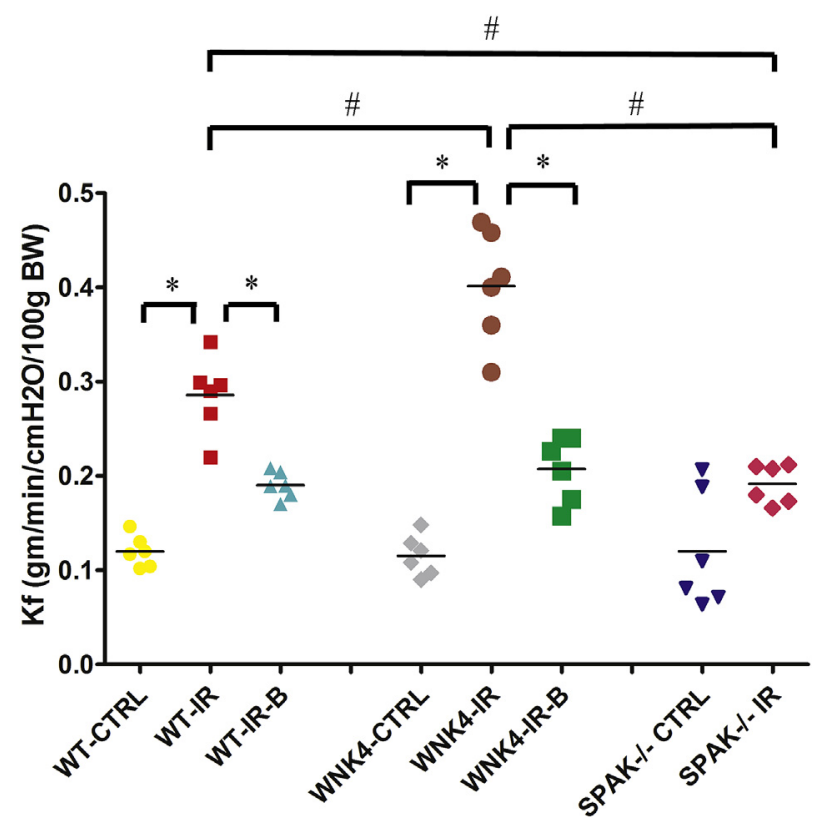

FIGURE 4. Kf after IR. Kf was similar across in control groups $(P>.05)$. Kf was significantly increased after IR in WT $(P<.05)$ and WNK4 $4^{\mathrm{D} 561 \mathrm{~A} /+}$ knockin mice $(P<.05)$, but not in $\mathrm{SPAK}^{-1-}$ mice $(P>.05)$. Bumetanide decreased IR-induced elevation of $\mathrm{Kf}$ in both $\mathrm{WNK} 4^{\mathrm{D} 561 \mathrm{~A} /+}$ knockin and WT mice $(P<.05$ compared with IR). *Significantly different from IR in each group $(P<.05)$. \#Significantly different among WT-IR, WNK4IR, and SPAK $^{-1-}$-IR $(P<.05) . K f$, Microvascular permeability; WT$C T R L$, WT with control; WT-IR, WT with IR; IR, ischemia-reperfusion; $W T-I R-B$, WT-IR with bumetanide; WNK4-CTRL, WNK4 $4^{\mathrm{D} 561 \mathrm{~A} /+}$ with control; WNK4-IR, WNK4 $4^{\mathrm{D} 561 \mathrm{~A} /+}$ with IR; WNK4-IR-B, WNK4 $4^{\mathrm{D} 561 \mathrm{~A} /+}-\mathrm{IR}$ with bumetanide; SPAK, STE20/SPS1-related proline/alanine rich kinase knockout; $S P A K^{-1-}-C T R L, \mathrm{SPAK}^{-1-}$ with control; $S P A K^{-1-}-I R, \mathrm{SPAK}^{-/-}$ with IR; $W N K 4^{D 561 A /+}$, with-no-lysine kinase 4 knockin; $W T$, wild-type.

IR in WT $(P>.05)$ and $\mathrm{WNK} 4^{\mathrm{D} 561 \mathrm{~A} /+}$ knockin mice $(P<.05)$, but not in SPAK ${ }^{-1-}$ mice $(P>.05)$. IR-induced elevations in $\mathrm{Kf}$ were decreased with bumetanide treatment in both WNK4 $4^{\mathrm{D} 561 \mathrm{~A} /+}$ knock-in and WT mice $(P<.05$ compared with IR). The microvascular hyperpermeability was less in $\mathrm{SPAK}^{-\prime-}$ or bumetanide-treated mice, which had lower NKCC1 function.

\section{Histopathologic Presentations After Ischemia-Reperfusion}

Histopathologic examinations were performed to verify the microanatomic features of lung injury imposed by IR (Figure 5) and to assess the influence of NKCC1 on neutrophil sequestration (Figure 6). Control groups had normal histology (Figure 5, $A-C$ ). Post-IR histopathology of WT (Figure 5, D) and WNK4 ${ }^{\mathrm{D} 561 \mathrm{~A} /+}$ mice (Figure 5, F) showed severe lung injury with pulmonary edema, alveolar wall thickening, and neutrophil sequestration. The degree of ALI was less severe in SPAK $^{-l-}$ mice (Figure $5, H$ ). The features of ALI in WT and WNK $4^{\mathrm{D} 561 \mathrm{~A} /+}$ mice were markedly attenuated by bumetanide (Figure 5, $E$ and $G$ ).
Neutrophil counts in the interstitium and alveoli were markedly increased in $\mathrm{WNK} 4^{\mathrm{D} 561 \mathrm{~A} /+}$ and $\mathrm{WT}$ mice after IR $(P<.05$ compared with control groups) (Figure 6, A). $\mathrm{SPAK}^{-1-}$ mice showed less neutrophil sequestration in the lungs compared with the WT-IR group $(P<.05)$. Bumetanide decreased IR-induced neutrophil sequestration in both WT and $\mathrm{WNK} 4^{\mathrm{D} 561 \mathrm{~A} /+}$ mice $(P<.05$ compared with IR). ALI scores were similar across control groups $(P>.05)$ (Figure 6, B). After IR, ALI scores were markedly increased in $\mathrm{WNK} 4^{\mathrm{D} 561 \mathrm{~A} /+}(P<.05$ compared with control $)$ and WT mice $\left(P<.05\right.$ compared with control) and less in $\mathrm{SPAK}^{-1-}$ mice $(P>.05$ compared with control). Bumetanide decreased ALI scores after IR in both WT and WNK $4^{\mathrm{D} 561 \mathrm{~A} /+}$ mice (both $P<.05$ compared with IR). The severity of ALI and neutrophil sequestration was less in $\mathrm{SPAK}^{-1-}$ or bumetanide-treated mice, which had lower NKCC1 function.

\section{Concentrations of Total Protein and \\ Proinflammatory Cytokines After \\ Ischemia-Reperfusion}

Total protein concentration in BALF, an indicator of vascular leakage, was significantly increased after IR $(P<.05)$ (Figure 7, $A$ ). Total protein concentration was higher in $\mathrm{WNK} 4^{\mathrm{D} 561 \mathrm{~A} /+}$ mice and lower in $\operatorname{SPAK}^{-1-}$ mice $(P<.05)$. Bumetanide decreased IR-induced elevation of total protein concentration in $\mathrm{WT}$ and $\mathrm{WNK} 4^{\mathrm{D} 561 \mathrm{~A} /+}$ mice $(P<.05$ compared with IR). MIP-2 and TNF- $\alpha$ levels were significantly higher after IR in WT $(P<.05)$ and WNK4 ${ }^{\mathrm{D} 561 \mathrm{~A} /+}$ mice $(P<.05)$ (Figure $7, B$ and $C$ ). SPAK $^{-1-}$ mice had less MIP-2 and TNF- $\alpha$ after IR $(P<.05$ compared with WT and $\mathrm{WNK} 4^{\mathrm{D} 561 \mathrm{~A} /+}$ mice post-IR). Bumetanide attenuated IRinduced increases in MIP-2 (both $P<.05$ compared with IR) and TNF- $\alpha$ (both $P<.05$ compared with IR). The concentrations of total protein and proinflammatory cytokines were less in $\mathrm{SPAK}^{-/-}$or bumetanide-treated mice.

\section{Nuclear Factor- $\kappa$ B Activation and Nuclear \\ Translocation After Ischemia-Reperfusion}

NF- $\kappa$ B p 65, I $\kappa$ B $-\alpha$, and phosphorylated IKK $\beta$ before and after IR are shown in Figure 8. After IR, the cytoplasmic levels of phosphorylated IKK $\beta$ and nuclear level of NF$\kappa \mathrm{B}$ p65 were increased $(P<.05)$. In contrast, $\mathrm{I} \kappa \mathrm{B}-\alpha$ levels were significantly reduced in $\mathrm{WT}$ and $\mathrm{WNK} 4^{\mathrm{D} 561 \mathrm{~A} /+}$ mice $(P<.05)$. Changes in NF- $\kappa \mathrm{B}$ p $65, \mathrm{I} \kappa \mathrm{B}-\alpha$, and phosphorylated IKK $\beta$ levels were not observed in SPAK ${ }^{-1-}$ mice. Bumetanide restored $\mathrm{I} \kappa \mathrm{B}-\alpha$ levels and reduced phosphorylated IKK $\beta$ and NF- $\kappa$ B p65 levels after IR in WT and WNK $4^{\mathrm{D} 561 \mathrm{~A} /+}$ mice $(P<.05$ compared with $\mathrm{IR})$. The NF$\kappa \mathrm{B}$ activation was less in $\mathrm{SPAK}^{-1-}$ or bumetanide-treated mice, which had lower NKCC1 function.

\section{DISCUSSION}

The findings of this study indicate that differences in expressions of NKCC1 influence the response to IR-induced 

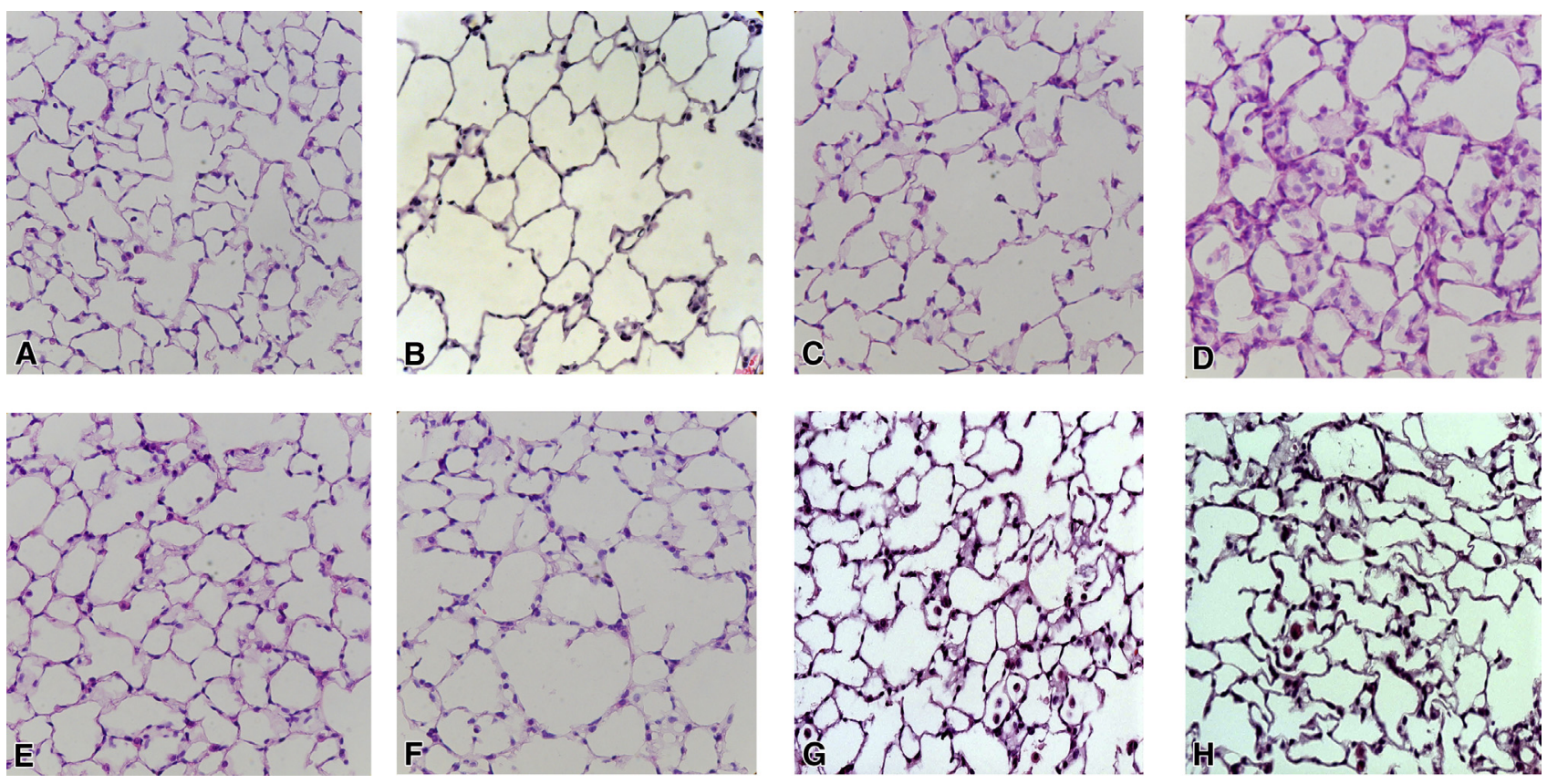

FIGURE 5. Histopathologic features in I/R-induced ALI. Control group of WT (A), WNK4 ${ }^{\mathrm{D} 561 \mathrm{~A} /+}$ knockin (B), and SPAK ${ }^{-1-}$ (C) mice had normal histology. After IR, there was severe lung injury with pulmonary edema, alveolar wall thickening, and neutrophil sequestration in WT (D) and WNK4 ${ }^{\mathrm{D} 561 \mathrm{~A} /+}$ knockin mice (F). Lung injury was markedly attenuated by bumetanide in WT (E) and WNK4 ${ }^{\mathrm{D} 561 \mathrm{~A} /+}$ knockin mice (G). Post-IR lung injury was not prominent in in $\mathrm{SPAK}^{-/-}$mice $(\mathrm{H}) . \mathrm{A}=\mathrm{WT}$-control, $\mathrm{B}=\mathrm{WNK} 4{ }^{\mathrm{D} 561 \mathrm{~A} / \mathrm{+}}$-control, $\mathrm{C}=\mathrm{SPAK}^{-/-}$-control, $\mathrm{D}=\mathrm{WT}-\mathrm{IR}, \mathrm{E}=\mathrm{WT}-\mathrm{IR}-$ bumetanide, $\mathrm{F}=\mathrm{WNK} 4^{\mathrm{D} 561 \mathrm{~A} /+}$-IR, $\mathrm{G}=\mathrm{WNK} 4^{\mathrm{D} 561 \mathrm{~A} /+}-$ IR-bumetanide, $\mathrm{H}=\mathrm{SPAK}^{-1-}-\mathrm{IR}$.

lung injury. Higher NKCC1 expression leads to more severe IR-induced ALI with increased pulmonary edema, higher $\mathrm{Kf}$, elevations in inflammatory cytokine levels, and increased neutrophil sequestration. Manipulations that decrease NKCC1 expressions were found to reduce the severity of lung injury. This study indicates that the WNK4-SPAK-NKCC1 pathway is important in regulating alveolar homeostasis and inflammation in IR-induced ALI.

Studies on the role of NKCC1 in IR-induced lung injury are lacking. It is suggested that $\mathrm{NKCC} 1$ regulates the lung endothelial and epithelial barriers, and modulates the inflammatory response to pneumonia and hyperoxiaassociated lung injury. ${ }^{20-22}$ Fluid regulation is critical in the development of pulmonary edema. The NKCC1 works to transport $\mathrm{Cl}^{-}$and is involved in the regulation of epithelial cell volume. ${ }^{23}$ Increased NKCC1 in lung injury results in cell swelling and retention of ions and fluid in the alveolar space resulting in aggravation of lung edema and injury. ${ }^{20}$ Solymosi and colleagues ${ }^{24}$ also identified $\mathrm{NKCC} 1$ as a $\mathrm{Cl}^{-}$entry channel with regulation of fluid transport. It is shown that the NKCC inhibitor, bumetanide, attenuates alveolar $\mathrm{Cl}^{-}$influx and blocks alveolar fluid secretion. ${ }^{24}$ Therefore, NKCC1 influences both inflammatory responses and fluid regulation. Upregulating $\mathrm{NKCC1}$ leads dysregulation of fluid transport and leads to cell swelling and inflammation. ${ }^{25,26}$ Cellular swelling results in apoptosis and membrane rupture. ${ }^{27}$ Consequently, apoptotic cells further release inflammatory mediators and proinflammatory cytokines. ${ }^{27}$ Therefore, higher NKCC1 expression in $\mathrm{WNK} 4^{\mathrm{D} 561 \mathrm{~A} /+}$ mice lead to a decrease in the rate of alveolar liquid absorption and resulted in more severe pulmonary edema after IR. Conversely, lower NKCC1 expression in $\mathrm{SPAK}^{-1-}$ mice showed resulted in less severe IR-induced lung injury.

The transcription factor NF- $\kappa$ B has a key role in SPAK regulation via an NF- $\kappa \mathrm{B}$ binding site in the 5'-flanking region of the SPAK gene. ${ }^{10}$ After IR the, NF- $\kappa$ B pathway is activated, which regulates proinflammatory cytokines and SPAK pathway. ${ }^{10}$ SPAK is important in epithelial transport, cell volume regulation, and cell survival. ${ }^{15}$ Activation of SPAK after IR may lead to aggravation of lung injury via 2 possible mechanisms: (1) As an upstream kinase, SPAK may phosphorylate and activate $\mathrm{NKCC} 1,{ }^{28}$ resulting in cell swelling, injury, and lung edema due to increased NKCC1 and SPAK activity after IR; and (2) activation of the p38 mitogen activated protein kinase (MAPK) pathway via SPAK, which leads to inflammation. ${ }^{15,28}$ Activation of the p38 MAPK pathway has been shown to correlate with apoptosis. ${ }^{29}$ Moreover, Wei and colleagues ${ }^{30}$ found that activation of p38 MAPK led to upregulation of inflammatory responses in lung injury and promoted inflammatory cytokines production. WNK4-SPAK-NKCC1 pathway is associated with cellular swelling and susceptibility to lung edema and injury after IR, ${ }^{25,26}$ as well as inflammatory 

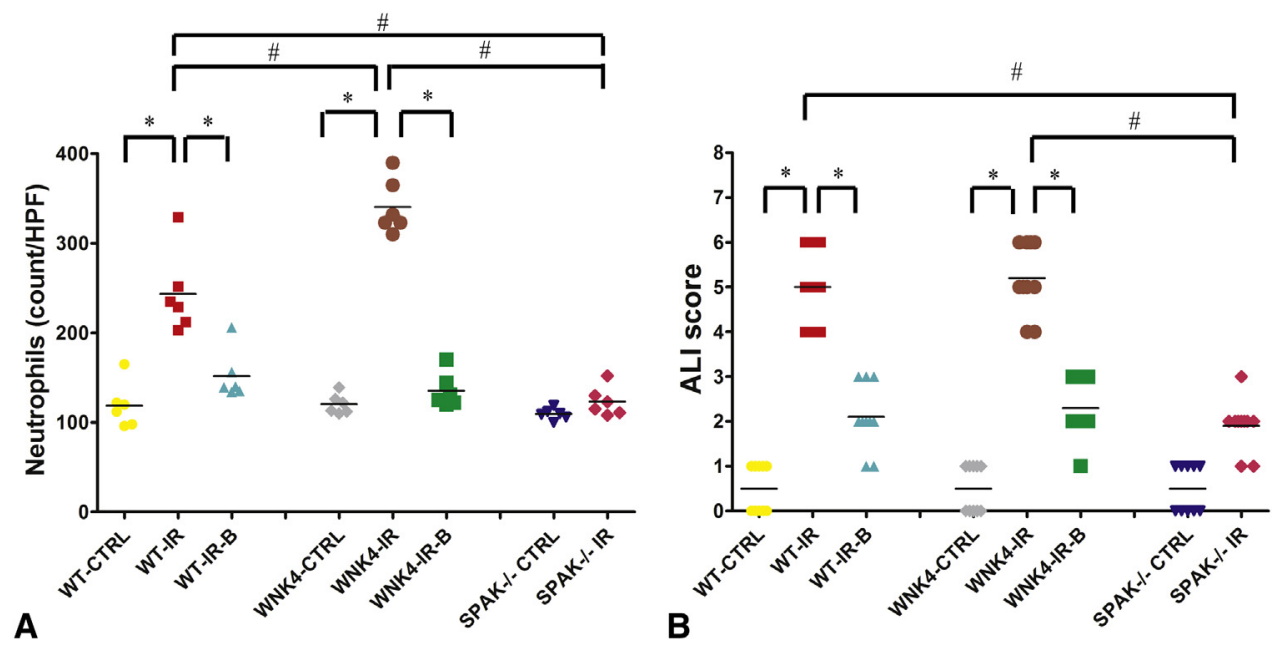

FIGURE 6. Pulmonary neutrophil sequestration after IR. A, Neutrophil count in lung tissue was lower in control groups. The neutrophil count was markedly increased in WNK4 ${ }^{\mathrm{D} 561 \mathrm{~A} /+}$ mice and WT mice after IR. Post-IR of SPAK ${ }^{-1-}$ mice had lower neutrophil count. Bumetanide decreased IR-induced neutrophil sequestration in both WT and WNK4 $4^{\mathrm{D} 561 \mathrm{~A} /+}$ mice $(P<.05$ compared with IR). B, ALI scores were similar across control groups $(P>.05)$. After IR, ALI scores were markedly increased in WNK4 ${ }^{\mathrm{D} 561 \mathrm{~A} /+}(P<.05$ compared with control $)$ and WT mice $(P<.05$ compared with control $)$ and less in $\mathrm{SPAK}^{-1-}$ mice $\left(P>.05\right.$ compared with control). Bumetanide decreased ALI scores after IR in both WT and WNK4 ${ }^{\mathrm{D} 561 \mathrm{~A} /+}$ mice $(\mathrm{both} P<.05$ compared with IR). *Significantly different from IR in each group $(P<.05)$. \#Significantly different among WT-IR, WNK4-IR, and SPAK ${ }^{-1-}-$ IR $(P<.05) . W T$, Wild-type; WT-CTRL, WT with control; WT-IR, WT with IR; IR, ischemia-reperfusion; WT-IR-B, WT-IR with bumetanide; WNK4-CTRL, WNK4 ${ }^{\mathrm{D} 561 \mathrm{~A} /+}$ with control; WNK4-IR, WNK4 $4^{\mathrm{D} 561 \mathrm{~A} /+}$ with IR; WNK4-IR-B, WNK4 $4^{\mathrm{D} 561 \mathrm{~A} /+}$-IR with bumetanide; SPAK, STE20/SPS1-related proline/alanine rich kinase knockout; $S P A K^{-1-}{ }_{-} C T R L$, SPAK ${ }^{-1-}$ with control; $S P A K^{-1-}-I R, \mathrm{SPAK}^{-1-}$ with IR; WNK4 ${ }^{D 56 I A /+}$, with-no-lysine kinase 4 knockin.

responses in lung injury. ${ }^{30}$ Consistent with these findings, IR-induced ALI was attenuated in $\mathrm{SPAK}^{-1-}$ mice or after administration of the NKCC1 inhibitor bumetanide in the present study.
Neutrophils play an essential role in the onset of ALI, ${ }^{31}$ and activation of NF- $\kappa \mathrm{B}$ pathway further increases neutrophil sequestration. ${ }^{10}$ Migration of neutrophils into the air spaces could be explained by a chemotactic effect of higher
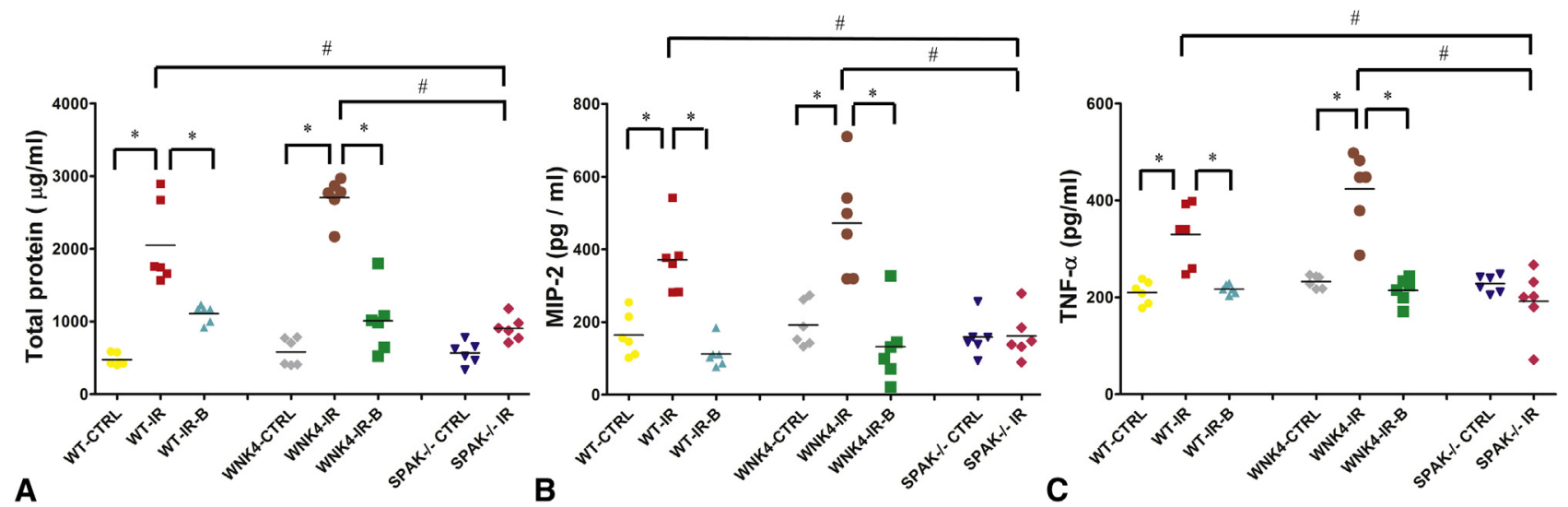

FIGURE 7. Concentrations of total protein and proinflammatory cytokines after IR. A, Total protein concentration in BALF was low in control groups. Total protein concentration significantly increased after IR in WT and WNK4 ${ }^{\mathrm{D} 561 \mathrm{~A} /+}$ mice $(P<.05)$ and lower in SPAK ${ }^{-/-}$mice. Bumetanide decreased IR-induced elevation of total protein concentration in WT and WNK4 $4^{\mathrm{D} 561 \mathrm{~A} /+}$ mice $(P<.05$ compared with IR). B, Concentration of MIP-2 was lower in control groups. MIP-2 levels were significantly higher after IR-induced ALI in WT $(P<.05)$ and WNK4 ${ }^{\mathrm{D} 561 \mathrm{~A} /+}$ mice $(P<.05)$. SPAK ${ }^{-/-}$mice had lower MIP-2 levels. Bumetanide attenuated IR-induced increase in elevation of MIP-2 (both $P<.05$ compared with IR). C, Concentration of TNF- $\alpha$ was lower in control group. TNF- $\alpha$ levels were significantly higher after IR-induced ALI in WT $(P<.05)$ and WNK4 ${ }^{\mathrm{D} 561 \mathrm{~A} /+}$ mice $(P<.05)$. SPAK ${ }^{-/-}$mice had lower TNF- $\alpha$ levels. Bumetanide attenuated IR-induced increase in TNF- $\alpha(P<.05$ compared with IR). *Significantly different from IR in each group $(P<.05)$. \#Significantly different among WT-IR, WNK4-IR, and SPAK ${ }^{-1-}$-IR $(P<.05)$. WT, Wild-type; WT-CTRL, WT with control; IR, ischemia-reperfusion; WT$I R$, WT with IR; WT-IR-B, WT-IR with bumetanide; WNK4 ${ }^{D 561 A /+}$, with-no-lysine kinase 4 knockin; WNK4-CTRL, WNK4 ${ }^{\mathrm{D} 561 \mathrm{~A} /++}$ with control; WNK4-IR, WNK4 $4^{\mathrm{D} 561 \mathrm{~A} /+}$ with IR; WNK4-IR-B, WNK4 ${ }^{\mathrm{D} 561 \mathrm{~A} /+}$-IR with bumetanide; SPAK, STE20/SPS1-related proline/alanine rich kinase knockout; SPAK ${ }^{-1-}$-CTRL, $\mathrm{SPAK}^{-1-}$ with control; SPAK ${ }^{-1-}-I R, \mathrm{SPAK}^{-1-}$ with IR; MIP, macrophage inflammatory protein-2; TNF- $\alpha$, tumor necrosis factor- $\alpha$. 

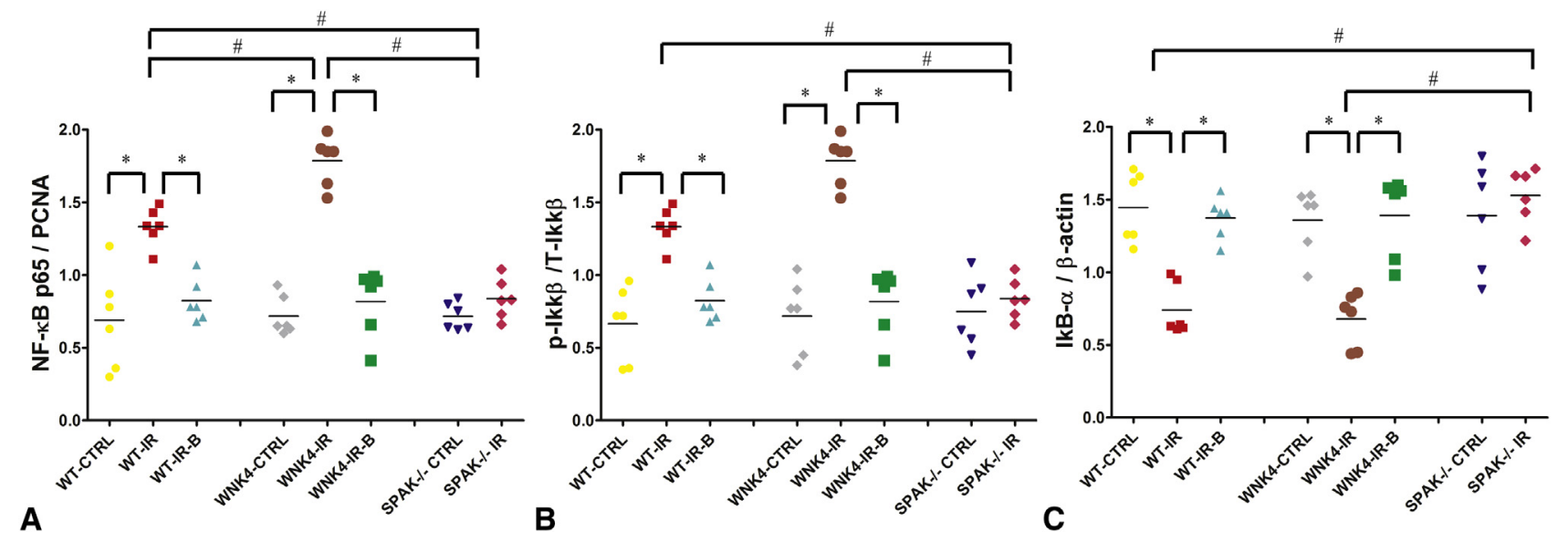

FIGURE 8. NF- $\kappa$ B activation and nuclear translocation after IR. After IR, the nuclear levels of NF- $\kappa$ B p65 (A) and cytoplasmic levels of phosphorylated $\operatorname{IKK} \beta(\mathrm{B})$ were increased, whereas the $\mathrm{I} \kappa \mathrm{B}-\alpha(\mathrm{C})$ levels were significantly suppressed in WT and $\mathrm{WNK} 4{ }^{\mathrm{D} 561 \mathrm{~A} /+}{ }^{\text {mice. }}$. Changes in NF- $\kappa \mathrm{B}$ p 65 , I $\kappa \mathrm{B}-\alpha$, and phosphorylated IKK $\beta$ levels were not prominent in SPAK ${ }^{-1-}$ mice. Bumetanide restored I $\kappa \mathrm{B}-\alpha$ levels and reduced phosphorylated IKK $\beta$ and NF- $\kappa \mathrm{B}$ p 65 levels after IR in WT and WNK4 ${ }^{\mathrm{D} 561 \mathrm{~A} /+}$ mice. *Significantly different from IR in each group $(P<.05)$. \#Significantly different among WT-IR, WNK4-IR, and $\mathrm{SPAK}^{-1-}$-IR $(P<.05) . N F-\kappa B$, Nuclear factor-kappaB; $W T$, wild-type; WT-CTRL, WT with control; IR, ischemia-reperfusion; WT-IR, WT with IR; WT$I R$ - $B$, WT-IR with bumetanide; WNK4 ${ }^{D 561 A /+}$, with-no-lysine kinase 4 knockin; WNK4-CTRL, WNK $4^{\mathrm{D} 561 \mathrm{~A} /+}{ }^{\text {with }}$ control; WNK4-IR-B, WNK4 ${ }^{\mathrm{D} 561 \mathrm{~A} /+}$-IR

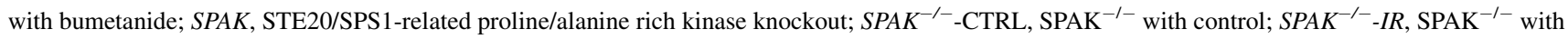
IR; I $K B$, Inhibitor of NF- $\kappa \mathrm{B} ; I K K, \mathrm{I} \kappa \mathrm{B}$ kinase.

proinflammatory cytokine levels in mice with greater NKCC1 expression. Moreover, neutrophils can degranulate and release toxic intracellular products, free radicals, and cytotoxic enzymes that lead to lung injury. ${ }^{17,31}$ The chemotactic effect of proinflammatory cytokines leads to migration of neutrophils into lung tissue. In WNK4 $4^{\mathrm{D} 561 \mathrm{~A} /+}$ mice with higher $\mathrm{NKCC1}$ expression, levels of proinflammatory cytokines and neutrophil sequestration are enhanced after IR and lead to more severe ALI. In $\mathrm{SPAK}^{-1-}$ mice with lower $\mathrm{NKCC1}$ expression, the levels of proinflammatory cytokines and neutrophil sequestration are attenuated and the severity of lung injury after IR is reduced.

Bumetanide is a potent loop diuretic that produces a rapid and marked diuresis and is often used for the treatment of pulmonary edema clinically. ${ }^{14}$ Pharmacologically, as a diuretic, bumetanide is approximately 40 -fold more potent than furosemide. ${ }^{14}$ In the clinical scenario, we cannot differentiate the effect of bumetanide through the kidney (as diuretics) or lung. By applying an isolatedperfused lung model, we can confirm that bumetanide clearly has an effect on the lung. NKCC1 regulates lung endothelial and epithelial barriers, and modulates the inflammatory response to lung injury. ${ }^{20-22}$ In our study, bumetanide-treated mice showed less lung inflammation and edema after IR. Previous studies also showed that administration of bumetanide in ALI reduces intracellular $\mathrm{Cl}$ - concentration and fluid content, and further reduces cell swelling. ${ }^{32,33}$ The beneficial effects of bumetanide not only regulate fluid transportation but also decrease lung inflammation.

\section{Clinical Implications}

Lung transplantation provides the hope of a curative option for many patients with end-stage pulmonary disease. Unfortunately, the shortage of donor organs remains a major limiting factor in its widespread application of lung transplantation. ${ }^{4}$ Despite advances in organ preservation, IR-induced ALI is one of the main causes of primary graft failure contributing to mortality after lung transplantation. ${ }^{5,6}$ Therefore, effective organ preservation is one of the key factors for successful lung transplantation. ${ }^{4}$ Although modern preservation techniques have revolutionized transplantation surgery, many investigators are still working toward a more reliable preservation method. In the present study, we suggested that by inhibiting NKCC1, bumetanide can attenuate IR-induced lung edema and injury. This investigation provides an impetus to consider approaches that address the role of NKCC 1 inhibitors in this clinical setting of lung transplantation. Akindipe and colleagues $^{34}$ also suggested the benefits of diuresis in lung transplant recipients with pulmonary edema. Therefore, we suggested the trial of bumetanide in the patients with lung injury or edema after lung transplantation.

\section{Study Limitations}

The present study has limitations in relation to the animal species and the isolated lung model used. However, by applying an isolated-perfused lung in situ, we can exclude the potential effects of NKCC1 in other organs. Thus, our data clearly highlight a role for NKCC1 in lung injury. However, further clinical studies on the roles of NKCC1 and the therapeutic effects of NKCC1 inhibition in IR-induced ALI 
in humans are warranted. Although endothelial function is known to be important in ALI, ${ }^{35}$ the relationship between epithelial NKCC1 and endothelial dysfunction remains unknown. Further studies are needed to determine the influence of NKCC1 on endothelial function.

\section{CONCLUSIONS}

IR-induced ALI presents with microvascular hyperpermeability, pulmonary edema, activation of NF- $\kappa$ B pathway, increased levels of proinflammatory cytokines, and neutrophil sequestration. The extent of NKCC1 expression in IR is associated with the level of activation of the NF- $\kappa \mathrm{B}$ pathway, amount of neutrophilic infiltration, and severity of lung injury. Functional reduction of NKCC1 by gene knockout or pharmacologic treatment with bumetanide to inhibit NKCC1 resulted in a lower severity of IR-induced ALI. Therefore, we suggest that alterations in NKCC1 function influence various inflammatory responses to IR. NKCC1 may present a promising target for pharmacologic interventions in a clinical setting.

\section{Conflict of Interest Statement}

Authors have nothing to disclose with regard to commercial support.

\section{References}

1. Weyker PD, Webb CA, Kiamanesh D, Flynn BC. Lung ischemia reperfusion injury: a bench-to-bedside review. Semin Cardiothorac Vasc Anesth. 2013;17: 28-43.

2. King RC, Binns OA, Rodriguez F, Kanithanon RC, Daniel TM, Spotnitz WD, et al. Reperfusion injury significantly impacts clinical outcome after pulmonary transplantation. Ann Thorac Surg. 2000;69:1681-5.

3. Huffmyer JL, Groves DS. Pulmonary complications of cardiopulmonary bypass. Best Pract Res Clin Anaesthesiol. 2015;29:163-75.

4. Tsuang WM, Vock DM, Finlen Copeland CA, Lederer DJ, Palmer SM. An acute change in lung allocation score and survival after lung transplantation: a cohort study. Ann Intern Med. 2013;158:650-7.

5. Hashimoto K, Kim H, Oishi H, Chen M, Iskender I, Sakamoto J, et al. Annexin V homodimer protects against ischemia reperfusion-induced acute lung injury in lung transplantation. J Thorac Cardiovasc Surg. 2016;151:861-9.

6. Machuca TN, Collaud S, Mercier O, Cheung M, Cunningham V, Kim SJ, et al. Outcomes of intraoperative extracorporeal membrane oxygenation versus cardiopulmonary bypass for lung transplantation. J Thorac Cardiovasc Surg. 2015; 149:1152-7

7. Topper JN, Wasserman SM, Anderson KR, Cai J, Falb D, Gimbrone MA Jr. Expression of the bumetanide-sensitive $\mathrm{Na}-\mathrm{K}-\mathrm{Cl}$ cotransporter $\mathrm{BSC} 2$ is differentially regulated by fluid mechanical and inflammatory cytokine stimuli in vascular endothelium. J Clin Invest. 1997:99:2941-9.

8. Russell JM. Sodium-potassium-chloride cotransport. Physiol Rev. 2000;80: 211-76.

9. Richardson C, Alessi DR. The regulation of salt transport and blood pressure by the WNK-SPAK/OSR1 signalling pathway. J Cell Sci. 2008;121:3293-304.

10. Yang R, Yang L, Shen X, Cheng W, Zhao B, Ali KH, et al. Suppression of NF- $\kappa$ B pathway by crocetin contributes to attenuation of lipopolysaccharide-induced acute lung injury in mice. Eur J Pharmacol. 2012;674:391-6.

11. Ross SD, Kron IL, Gangemi JJ, Shockey KS, Stoler M, Kern JA, et al. Attenuation of lung reperfusion injury after transplantation using an inhibitor of nuclear factor-kappa B. Am J Physiol Lung Cell Mol Physiol. 2000;279:L528-36.

12. Yang SS, Morimoto T, Rai T, Chiga M, Sohara E, Ohno M, et al. Molecular pathogenesis of pseudohypoaldosteronism type II: generation and analysis of a Wnk4 $4^{\mathrm{D} 561 \mathrm{~A} /+}$ knockin mouse model. Cell Metab. 2007:5:331-44.

13. Thastrup JO, Rafiqi FH, Vitari AC, Pozo-Guisado E, Deak M, Mehellou Y, et al. SPAK/OSR1 regulate NKCC1 and WNK activity: analysis of WNK isoform in- teractions and activation by T-loop trans-autophosphorylation. Biochem J. 2012 441:325-37.

14. Nappi JM. A retrospective evaluation of the efficacy of intravenous bumetanide and comparison of potency with furosemide. Pharm Pract(Granada). 2013;11: 44-50.

15. Johnston AM, Naselli G, Gonez LJ, Martin RM, Harrison LC, DeAizpurua HJ SPAK, a STE20/SPS1-related kinase that activates the p38 pathway. Oncogene. 2000;19:4290-7.

16. Vanderpool RR, Naeije R, Chesler NC. Impedance in isolated mouse lungs for the determination of site of action of vasoactive agents and disease. Ann Biomed Eng. 2010;38:1854-61.

17. Khimenko PL, Bagby GJ, Fuseler J, Taylor AE. Tumor necrosis factor-alpha in ischemia and reperfusion injury in rat lungs. J Appl Physiol. 1998;85: 2005-11.

18. Huang KL, Chen CS, Hsu CW, Li MH, Chang H, Tsai SH, et al. Therapeutic effects of baicalin on lipopolysaccharide-induced acute lung injury in rats. Am J Chin Med. 2008;36:301-11.

19. Wu SY, Li MH, Ko FC, Wu GC, Huang KL, Chu SJ. Protective effect of hypercapnic acidosis in ischemia-reperfusion lung injury is attributable to upregulation of heme oxygenase-1. PLoS One. 2013;9:e74742.

20. Matthay MA, Su X. Pulmonary barriers to pneumonia and sepsis. Nat Med. 2007; 13:780-1.

21. Andrade L, Rodrigues AC Jr, Sanches TR, Souza RB, Seguro AC. Leptospirosis leads to dysregulation of sodium transporters in the kidney and lung. Am J Physiol Renal Physiol. 2007;292:F586-92.

22. Lin HJ, Wu CP, Peng CK, Lin SH, Uchida S, Yang SS, et al. With-no-lysine kinase 4 mediates alveolar fluid regulation in hyperoxia-induced lung injury. Crit Care Med. 2015;43:e412-9.

23. O'Donnell ME. Role of Na-K-Cl cotransport in vascular endothelial cell volume regulation. Am J Physiol. 1993;264:C1316-26.

24. Solymosi EA, Kaestle-Gembardt SM, Vadász IWL, Neye N, Chupin CJ Rozowsky S, et al. Chloride transport-driven alveolar fluid secretion is a major contributor to cardiogenic lung edema. Proc Natl Acad Sci. 2013;110:E2308-16.

25. O'Donnell ME, Tran L, Lam TI, Liu XB, Anderson SE. Bumetanide inhibition of the blood-brain barrier $\mathrm{Na}-\mathrm{K}-\mathrm{Cl}$ cotransporter reduces edema formation in the rat middle cerebral artery occlusion model of stroke. J Cereb Blood Flow Metab. 2004;24:1046-56.

26. Nguyen M, Pace AJ, Koller BH. Mice lacking NKCC1 are protected from development of bacteremia and hypothermic sepsis secondary to bacterial pneumonia. J Exp Med. 2007;204:1383-93.

27. Martin TR, Hagimoto N, Nakamura M, Matute-Bello G. Apoptosis and epithelial injury in the lungs. Proc Am Thorac Soc. 2005;2:214-20.

28. Yang SS, Lo YF, Wu CC, Lin SW, Yeh CJ, Chu P, et al. SPAK-knockout mice manifest Gitelman syndrome and impaired vasoconstriction. J Am Soc Nephrol. 2010;21:1868-77.

29. Hao W, Wang S, Zhou Z. Tubeimoside-1 inhibits lung cancer cell growth and induces cells apoptosis through activation of MAPK-JNK pathway. Int J Clin Exp Pathol. 2015;8:12075-83.

30. Wei D, Huang ZH, Zhang RH, Wang CL, Xu MJ, Liu BJ, et al. Roles of p38 MAPK in the regulation of the inflammatory response to swine influenza virus-induced acute lung injury in mice. Acta Virol. 2014;58:374-9.

31. den Hengst WA, Gielis JF, Lin JY, Van Schil PE, De Windt LJ, Moens AL. Lung ischemia-reperfusion injury: a molecular and clinical view on a complex pathophysiological process. Am J Physiol Heart Circ Physiol. 2010;299: H1283-99.

32. Hannaert P, Alvarez-Guerra M, Pirot D, Nazaret C, Garay RP. Rat NKCC2/ NKCC1 cotransporter selectivity for loop diuretic drugs. Naunyn Schmiedebergs Arch Pharmacol. 2002;365:193-9.

33. Gillie DJ, Pace AJ, Coakley RJ, Koller BH, Barker PM. Liquid and ion transport by fetal airway and lung epithelia of mice deficient in sodium-potassium-2chloride transporter. Am J Respir Cell Mol Biol. 2001;25:14-20.

34. Akindipe O, Fernandez-Bussy S, Staples ED, Baz M. Late unilateral pulmonary edema in single lung transplant recipients. J Heart Lung Transplant. 2008;27:1055-8.

35. Aird WC. The role of the endothelium in severe sepsis and multiple organ dysfunction syndrome. Blood. 2003;101:3765-77.

Key Words: acute lung injury, ischemia-reperfusion injury, nuclear factor- $\kappa \mathrm{B}$, sodium-potassium-chloride co-transporter isoform 1, STE20/SPS1-related proline/alanine rich kinase, with-no-lysine kinase 4 